in a brief but comprehensive discussion of the problems of electrolyte and fluid balance it is a pity that an apparently commendatory reference is made to Coller and Maddock's 'clinical rule' for the replacement of electrolyte deficits without reference to the fact that these same authors rescinded this rule in a paper written in 1944.

Such criticisms, however, in no way detract from the outstanding merit and value of this book, which cannot fail to interest all those concerned in this important branch of medicine. It is a volume to which physicians and surgeons will constantly turn for stimulus and information. It is a pity that we live in such times that 5 gns. must be expended in obtaining this magnificently produced book.

\section{STATISTICS FOR MEDICAL AND OTHER BIOLOGICAL STUDENTS}

By L. Bernstein, B.Sc., M.R.C.S., L.R.C.P., and M. Weatherall, M.A., D.M., B.Sc. Pp. xii + r8o. Edinburgh: F. \& S. Livingstone. 1952. $18 \mathrm{~s}$.

This book is an admirable introduction to statistics. There is a welcome emphasis on the need for planning throughout the whole course of an investigation, and the analysis of results is seen as merely the final step in the statistical discipline. However it seems to the reviewer that this book will appear too formidable to the general run of medical students. There is a tendency to approach problems from their more theoretical aspects rather than to lead gently up to them with examples of medical interest. This criticism derives from the ingrained prejudice that statistics are an independent discipline and that the medical student must therefore be wooed in order to participate. In factstatistical thinking should permeate medical thought, and as the authors point out, this must be achieved by the use of statistics as an integral part of all pre-medical and medical training. Statistics should not be taught as an independent subject, but should be introduced by every teacher whenever relevant.

\section{ORTHOPAEDIC NURSING}

By Mary Powell, S.R.N., M.C.S.P. Pp. xii + 400. Edinburgh: E. \& S. Livingstone. I 95 I. $25 \mathrm{~s}$.

The quality of the training in orthopaedic nursing and after-care imparted by the staff of the Dame Agnes Hunt and Robert Jones Hospital at Oswestry is a by-word throughout the British Isles and, indeed, the Commonwealth. Miss Powell's profusely illustrated book reflects every aspect of the well-tried methods of the Oswestry School and provides a record which all tutor sisters and many nurses and orthopaedic surgeons will wish to read. Particular attention is paid to the correct use of those classical pieces of equipment, the Thomas bed knee splint and the Jones' double abduction frame, and to more recent techniques such as the Watson-Jones treatment of compression fractures of the lumbo-dorsal spine by hyperextension and the application of a plaster jacket.
The methods used in other centres, however, ڤ vary quite considerably from those collated by Miss Powell, and leading orthopaedic surgeons may be尺 found who have abandoned the Thomas splint for:. a fractured shaft of femur in favour of Hamilton- $\overrightarrow{\vec{F}}$. Russell traction, who seldom use a frame for $a \stackrel{\text { ? }}{\rightarrow}$ tuberculous spine because they find an anterior or posterior plaster bed so simple, comfortable and흐 effective or who for a variety of reasons never $\frac{\bar{S}}{}$. hyper-extend a compression fracture of the lumbar $\mathbb{\phi}$ spine. But too wide a choice often makes for con- $\frac{a}{0}$ fusion, and for this reason Miss Powell's clear's record of Oswestry's systematic teaching is all the $\overrightarrow{0}$ more welcome.

K.I.N.

\section{MALIGNANT DISEASE AND ITS} TREATMENT BY RADIUM. VOL. 4

By Sir Stanford Cade, K.B.E., C.B., F.R.C.S., M.R.C.P. 2nd Edition. Pp. xv +544 , with 785 illustrations. Bristol : John Wright \& Sons. 1952. 635 .

This fourth volume of Sir Stanford Cade's encyclopaedic monograph on malignant disease and $N$ its treatment by radium is of particular interest for $\frac{}{2}$ many reasons.

It includes chapters on subjects which have $\bar{z}$ always been particularly personal interests of the author's and some of these chapters reflect an $\vec{\varphi}$ experience which must be regarded as unique in if extent. This particularly applies to bone sarconia (consideration of which is based on 164 patients figures), sarcomas of soft tissue and tumours of the testis. The volume is important, too, because it includes the author's views on malignant tumours of the skin, illustrated also by a very vast experience. $\frac{\mathrm{D}}{\mathrm{D}}$

The author, in public debate, has established a reputation for ardent advocacy and powerful $\overrightarrow{\overrightarrow{0}}$ rhetoric. His literary style can on occasion be just as forceful and dramatic; it is a tribute to his capacity for private judicial contemplation that he affords in this work a most balanced and unbiased judgment.

The volume includes chapters on the tumours of lymphoid tissue by George Lumb and F. M. Allchin, on the leukaemias by B. W. Windeyer and J. W. Stewart, and on intracranial tumours by Denis Williams, Wylie McKissock and Jackson 0 Richmond.

This volume, like its predecessors, is eminently $\frac{D}{O}$ readable and the vast amount of factual knowledge which it contains is arranged with masterly general- N ship. The production is of the highest order and 5 the illustrations have a perfect clarity both in respect $N$ of microphotographs and X-ray reproductions. N Colour has been liberally employed and many original diagrams are very valuable. The work as a whole will be read with profit and retained for $\stackrel{O}{=}$ frequent reference by surgeons, pathologists and $\mathscr{\Phi}$ radiotherapists. It can safely be regarded as a standard account of the whole field of treatment of 70 malignant disease today and it contributes substantially to the natural history of cancer and to descriptive and statistical oncology.

I.A. 